\title{
Towards a philosophy of public health
}

\author{
Douglas L Weed
}

A few years ago, readers of the journal were invited to discuss the philosophical foundations of public health. ${ }^{1}$ This invitation was accompanied - indeed, justified - by the claim that the disclosure of philosophical perspectives is essential to the resolution of complex issues in public health. The authors, Nijhuis and Van der Maesen, argued that debates about the pros and cons of public health approaches are often confined to the methodological scientific level, thereby neglecting implicit ontological notions lying behind and presumably influencing the arguments and decisions flowing from them. Consistent with this view is the idea that public health experts would make better choices if only they would disclose their ontological orientation towards the paired notions of "public" and "health." Four categories of ontological interpretations of public health were offered: two "public" categories and two "health" categories. "Public" category no 1 emphasises the individual. In this view, the public is primarily comprised of the actions and motives of discrete individuals. "Public" category no 2, on the other hand, emphasises the collective over the individual. In this view, the public is primarily conceived as populations within social, economic, and political systems. "Health" category no 3 is a mechanistic view that emphasises the traditional medical distinction between disease and non-disease in the individual, whereas category no 4 views health as the degree to which an individual reaches an equilibrium state with somatic, psychological, and social influences. Much more could be said about these four categories. Categories no 1 and no 2, for example, could be retrofitted into Rose's classic paper on sick individuals and sick populations. ${ }^{2}$ And Nijhuis and Van der Maesen's idea that most scientific work in epidemiology emphasises categories no 1 and no 3 whereas most health policy work emphasises categories no 2 and no 4 may reflect the considerable distance between the current practice of epidemiology and the practice of public health that has recently attracted so much attention..$^{3-5}$ In any case, it is reasonable to consider how revealing one's commitment to these various categories influences practical public health decision making.

Perhaps to encourage further discussion, Nijhuis and Van der Maesen did not illustrate their "disclosure claim" with an example of how a public health decision was made better (or a complex debate resolved) by revealing the ontological orientation(s) of the decisionmaker. Yet many potential examples exist. Consider the general situation for public health interventions in which the benefit to the individual is small relative to the benefit to society. Applying a strict interpretation of
Nijhuis and Van der Maesen's claim to this situation would make decision making about the appropriateness of the intervention reasonably straightforward. An intervention is less likely to be advocated if the primary ontological orientation of the decision maker is with the individual-category no 1 - than if the decisionmaker is committed to the populationcategory no 2 .

"Real life" public health decisions are obviously much more complex, no more isolated matters of ontology than they are isolated matters of scientific methodology. Indeed, there is probably more to the philosophical basis of decisions than ontological concerns alone. This disclosure claim, therefore, can and should be expanded to include other types of philosophical commitments. Ethics seems particularly relevant in as much as public health decisions often entail balancing benefits and risks to individuals and to society, an initial condition for the decision described above. Public health decisions may also be affected by the practitioner's orientations in the shifting epistemological sands of the philosophy of science.

In this paper, I expand the "disclosure claim" of Nijhuis and Van der Maesen to include not only ontological but also ethical and epistemological perspectives. Brief definitions of these three philosophical categories may assist the reader who is unfamiliar with this territory.

Ontology

Involves the nature or essence of reality, of being and existence.

\section{Ethics}

Involves the nature of rightness and the study of what actions are right actions.

\section{Epistemology}

Involves the study of how knowledge is gained, and the general validity of claims to knowledge.

Each is a highly developed theoretical discipline in its own right and each can also be connected to (that is, applied to) issues within the theory and practice of public health. For example, Nijhuis and Van der Maesen's four ontological interpretations relate to the nature of the essential concepts of "public" and "health." The nature of causation is also an ontological concern, but how knowledge is gained about causation is an epistemological concern. Epistemological commitments to forms of logic (for example, induction or deduction) or to other theoretical approaches may influence how scientific evidence that tests causal hypotheses is examined or interpreted. 
Ethics, the study of what constitutes right actions, also has its theoretical side, but may be the most "applied" of these philosophical categories. Making and justifying decisions about what ought to be done in particular situations (that is, cases) is a familiar application of ethics to public health practice.

In the examples that follow, it will become clear that these different philosophical arenas are not easily separated from one another. Independence is more a matter of theoretical than practical interest in everyday decision making. It follows that the future practice of public health decision making may benefit from a mix of ontological, ethical, and epistemological perspectives informed by a general philosophy of public health. This paper will not go so far as to propose such a general theory yet may help set the stage for such an effort. I begin with an example of public health decision making affected by a mix of ontological and ethical perspectives. In the second example, I add epistemological concerns. Clearly there is not room to explore deeply these philosophical roots. My purpose is rather to draw attention to several aspects of practical decision making that, as will be shown below, cannot be easily dismissed.

\section{Ontology and ethics}

In public health decision making, ontological and ethical perspectives are intertwined. Consider cancer screening as a prototypical example (and assume that the efficacy of the screening test and its side effects are known-that is, not controversial-thereby excluding epistemological concerns from the analysis). Implementation of a mass screening programme, for example, breast cancer screening by mammography or cholesterol screening for heart disease, entails wide public promotion of an intervention. At first glance, two ontological categories proposed by Nijhuis and Van der Maesen undergird the public health decision to go forward with such programmes: the population (as a collective), category no 2 , and health promotion, category no 4 .

These two perspectives, however, are insufficient to make decisions about the appropriateness of an intervention, even in those circumstances in which efficacy is accepted. There are concerns about the trade off between benefits to the population (the collective) and risks (that is, harms) to the individuals comprising the population. As Rose has argued, individuals typically fare less well than the population for prevention programmes ${ }^{6}$; he dubbed this situation the "prevention paradox." There are also concerns about the extent to which individual decisions to undergo the intervention are autonomous - that is, not coerced.

Bringing "individuals" into the discussion, however, signals the need to consider ontological category no 1 , the gestalt of individuals. Similarly, bringing "risk" into the discussion is a direct reflection of the natural scientific or mechanistic notion of health (category no 3 ) in as much as cancer screening involves side effects to individuals such as direct injury from the screening test itself, or residual physical trauma from treatment that may be needed if a positive diagnosis is made. In prostate cancer screening, for example, incontinence and impotence are important risks of treatment. Yet "risk" could also reflect a more holistic notion of health (category no 4) because it involves psychological trauma such as anxiety, an increasingly recognised issue in cancer screening.

It seems, therefore, that there are choices to be made regarding specific public health interventions - here, cancer screening testswherein all four ontological interpretations found in Nijhuis and Van der Maesen's paper ${ }^{1}$ are relevant if not often explicitly labelled as philosophical perspectives in themselves. How to make the best decisions in a given situation, especially given the inherent dilemmas such as the prevention paradox, must therefore entail something more than ontology alone, as we suspected from the earlier and simpler example. There is a need to balance the individual's perspective, emphasising autonomy, self determination, and safety against the perspective of the collective with its responsibility to intervene to increase the overall health of its citizenry ${ }^{8}$ for the common good. ${ }^{9}$ This balancing, however, largely takes place in ethical terms. Rules to "help others" and to "prevent harm to others" are involved and are derived from the general principle of beneficence. Also involved is the principle of respect for persons that is made manifest when information regarding potential risks and benefits ${ }^{10}$ is provided so that individuals may decide for themselves whether to participate or not in a screening programme. Thus, in practical public health decision making, a combination of ontological categories and ethical constructs are important, consistent with but expanding upon Nijhuis and Van der Maesen's claim.

The expansion of the disclosure claim, however, does not deny the importance of a basic distinction between the individual and the population in public health. Legislatively mandated public health programmes, for example, highlight this stark contrast. Seat belt laws, immunisation requirements, and mandatory reporting of sexually transmitted diseases are three American examples; each involves considerable restraints on the individual for the benefit of the population. Nevertheless, the justification for these actions-which are enforceable by the power of the state, and which are tax supported and intrusive-involves more than ontology. Cole, for example, argues that commonweal, or "doing the greatest good for the greatest number" is the justification for abrogating the rights of individuals. ${ }^{11}$ Pellegrino ${ }^{12}$ provides the view that legislated public health interventions almost always involve a trade off between commitments to general and widely used (if somewhat battered) ethical principles; typically, a paternalistic beneficence is enlisted to limit personal autonomy. Last ${ }^{13}$ also offers beneficence as a dominant ethical principle in public health but balances it with a respect for the autonomy of people. He notes that it is important to provide them with sufficient information to empower 
them to do what they can to promote health rather than coercing them to stop doing what they find pleasurable or to start doing what they find unacceptable.

\section{Ontology, ethics, and epistemology}

Epistemological perspectives also lie unrecognised and undisclosed in the philosophical closets of public health decision makers. ${ }^{14}$ Consider, for example, the idea ${ }^{13}$ that health promotion for the benefit of populations should be based on solid evidence of efficacy. Brought together in this statement are underlying and implict epistemological commitments, for example, the nature of evidence and its relation to the hypotheses being tested, the meaning of "solid" and "efficacy" as well as ontological concerns (for example, populations) and ethical perspectives (for example, benefit). In keeping with the idea that commitments to any one or a combination of these three philosophical arenas can affect public health decision making, I will show how different published opinions about an important public health issue are at least consistent with different perspectives, some ontological, some ethical, and some epistemological. In most instances, the decision maker's awareness of the philosophical underpinnings of his individual decision (and whether he would accept Nijhuis and Van der Maesen's disclosure claim) is a matter for speculation. In a few papers, on the other hand, decision makers have identified philosophical constructs, evidence that Nijhuis and Van der Maesen's claim has some (perhaps unwitting) advocates in practice.

The example is cancer screening with prostate specific antigen (PSA). Stark differences exist among organisations and among individual commentators regarding whether PSA screening should be recommended. ${ }^{15}$ For the purposes of this paper, I examine only published individual decisions, leaving institutional decisionmaking for another time. There is no shortage of examples. In 1993, the British Medical fournal published an editorial in which the author-Schroder-states that "....(PSA) screening should not be recommended...."16 The same year, Urology published an editorial in which the author-Catalona-presents precisely the opposite opinion, that "....screening with an annual rectal examination and serum PSA measurement should be encouraged...."17 Four years later, the situation has not changed much. Just one example is a pair of commentaries appearing in the European fournal of Cancer, one arguing against ${ }^{18}$ and another arguing for the "gold standard" status of prostate cancer screening. ${ }^{19}$

What philosophical orientations, whether epistemological, ethical, or ontological, underlie these very different opinions? Answering this question will require a careful examination of the exact wording from decision makers, inferring from them what philosophical commitments are, if not explicitly stated, then are at least consistent with those opinions. I begin with epistemological concerns, because all current published opinions have appeared while
KEY POINTS

- Philosophical perspectives underlie and influence complex decisions in public health but are rarely described by decision makers.

- Ontological perspectives involve the nature of causation and the meanings of "public" and "health."

- Ethical perspectives involve the basis for making decisions about what ought to be done to improve the public's health.

- Epistemological perspectives involve how knowledge is gained about cause through the interpretation of scientific evidence.

- A general philosophy of public health, with ontological, ethical, and epistemological components, would provide a new foundation for public health decision making.

randomised trials of PSA screening ${ }^{20} 21$ and a randomised trial of surgery compared with expectant management for localised disease ${ }^{22}$ have been undertaken. No trial has been completed. It follows that all published recommendations (to screen or not) either deny or accept the need for a strong (RCT) test of the hypothesis that PSA screening reduces mortality. Put in the language of the expanded "disclosure claim," none of these decisions are made without at least an implicit epistemological position about the need for randomised trial evidence. Four published opinions follow:

Schroder, the 1993 British Medical fournal editorialist, makes clear his perspective when he writes that "....(PSA) screening should not be recommended as public health policy until clear benefit in terms of reduced mortality from cancer can be shown in prospective screening studies...." Voss, a 1994 editorialist in the Fournal of General Internal Medicine ${ }^{23}$ provides a similar view when he writes that annual PSA tests are "not warranted by the available evidence." In both instances, there is a clear epistemologically oriented criterion: no positive trial results means no screening recommendation. Others differ in their evidentiary threshold. Catalona, who wrote the 1993 Urology editorial mentioned earlier, notes that "the National Cancer Institute is conducting a prospective randomised trial to determine whether or not screening reduces the prostate cancer mortality rate, but it will take sixteen years to complete the study. It is estimated that half a million men will die of prostate cancer before this study is completed, and it is unreasonable to expect clinicians to refrain from PSA testing in the meantime."13 More recently, an Annals of Internal Medicine editorialistMiddleton-justifies his decision to support screening with the following: "we do not know whether our efforts will ultimately reduce mortality related to prostate cancer, but we can be hopeful." He cites SEER data showing a decrease in the incidence of new cases of metastatic disease. ${ }^{24}$

These examples reveal something about the methodological requirements of these decision 
makers but nothing about their epistemological commitments in themselves. According to Vineis, however, different epistemological perspectives may lead to different methodological requirements. He believes that an empiricist philosophy requires randomised trial evidence whereas other philosophical perspectives may only require mechanistic evidence. ${ }^{25}$ The relations between epistemological commitments and methodological choices or evidentiary thresholds is a rich area for further exploration. What, for example, are the epistemological roots of the hierarchies of study design so often promoted in evidence-based medicine and evidence-based public health? What are the epistemological roots of causal criteria ${ }^{14}$ While specific answers to these sorts of questions are beyond the scope of this paper, it is nevertheless reasonable to suppose that the different decisions about PSA screening could be affected by different epistemological perspectives made manifest in different methodological requirements.

Unfortunately, no such epistemological commitments are outlined. And, it is probably too simplistic to argue that methodological commitments (or their roots in different epistemological frameworks if we knew them) completely determine the opinions held about PSA screening. In each example, there are implicit ethical notions and there are also suggestions of ontological commitments along the lines suggested by Nijhuis and Van der Maesen. Schroder, for example, notes that screening should not be recommended "as public health policy." 16 Catalona, as noted above, recommends that clinicians should not refrain from PSA testing but says nothing about public health screening programmes outside the context of the physician-patient relationship. ${ }^{17}$ Voss $^{23}$ notes that annual PSA tests are not warranted for asymptomatic patients. Middleton ${ }^{24}$ subscribes to the ACS recommendation that a man older than 50 years should have a PSA test and that recommendation clearly states that it is not intended as a guideline for public health policy. ${ }^{26}$

It seems, therefore, that a careful examination of published opinions on the appropriateness of PSA screening shows not only subtle commitments to epistemological and ontological frameworks but also somewhat less contentiousness than what was apparent on the surface. These published opinions appear to collect into two camps: those who argue against mass public screening programmes and those who argue for screening as a part of routine clinical practice.

The PSA controversy has also included a few papers in which explicit attention has been paid to philosophical perspectives. Chodak, for example, in a relatively early paper, ${ }^{27}$ notes that the lack of scientific evidence in support of a mortality reduction (an epistemological claim) does not satisfy the Hippocratic tradition of non-maleficence because screening harms a significant number of men (an ethical claim). $\mathrm{He}$ notes that screening asymptomatic men refers to both public programmes and to situa- tions involving individual patients (an ontological claim). He concludes that the most balanced approach does not involve making strong recommendations for mass screening. For patients, he recommends discussing the nature of the controversy and the potential advantages and disadvantages of screening and treatment, allowing the patient to help make the decision to screen or not. Woolf ${ }^{28} 29$ as well as Hahn and Roberts ${ }^{30}$ also support this "informed consent" model for asymptomatic men who present at a physician's office. Interestingly, a recent study has shown that men informed about PSA testing are less interested in undergoing those tests than controls. ${ }^{31}$

\section{Conclusion}

So it seems that published decisions about the appropriateness of PSA screening have at their heart issues of epistemology, ethics, and ontology. I doubt that other public health interventions are different. Each such decision is a matter of concern (call it respect) for the person or population involved (a combination of ontological and ethical concerns) and it is about the benefits and risks of intervention (a combination of ethical and epistemological concerns, and according to Nijhuis and Van der Maesen, also a matter of ontology). The extent to which decision makers provide their philosophical orientation appears to assist us in understanding their decision; it remains an unresolved and more difficult issue whether decisions consistent with Nijhuis and Van der Maesen's "disclosure claim" are in fact better decisions. To make matters even more complex, decisions about interventions are affected by more than philosophical perspectives. There are powerful economic interests for researchers and for medical practitioners alike. Aronowitz recently argues that extensive investments of research money give researchers as much to gain by not recommending PSA screening as physicians have to gain through reimbursements by recommending it. ${ }^{32}$ Along these lines, it is interesting to note that Schroder ${ }^{16}$ (who does not support public screening) is the principal investigator of a large trial testing PSA screening. Catalona ${ }^{17}$ and Middleton ${ }^{24}$ are both practising urologists and both advocate screening for asymptomatic men. Without frank disclosure on the part of these individuals, it is not clear if these are compelling interests or not. What is clear is that Nijhuis and Van der Maesen's disclosure claim will require further expansion beyond philosophical foundations to include economic interests, political ideologies, and other social forces. Aronowitz sums it up: "...the best recommendations will be those that take into account the complex ideologic, social and political forces that shape our response to specific health issues." 32

\section{Towards a philosophy of public health}

Although we cannot clearly demonstrate that decisions about public health interventions would have been better had philosophical perspectives been made explicit, the claim is consistent with research that has shown that, for ethics, the more you know the more likely you 
are to make ethically appropriate decisions. ${ }^{33} 34$ It follows that in order for these philosophical perspectives to be recognised by public health decisionmakers, to be made explicit, and to make a difference in practical decision making, they should be incorporated into the formal training and career development programmes of the public health professions. ${ }^{4}$

Not everyone agrees that philosophy can be taught nor that it is relevant to practice. Schlesinger, for example, writes that scientists' problem solving skills are not likely to be improved by studying the philosophy of science. He suggests that inspiration and a type of mental exhilaration are the primary benefits of philosophical inquiry. ${ }^{35}$ And perhaps the interest epidemiologists and other public health practitioners have expressed in philosophical issues in the past two decades can be explained in such terms, although I find more satisfying the notion that by describing the ontological nature of causal (and other types of) hypotheses, the epistemological framework for testing those hypotheses, and the ethical foundation for applying that knowledge we will be rewarded with a better understanding and perhaps even justifications for the difficult decisions we make in the practice of public health. In the absence of such an effort, we are left with the important but poorly characterised constructs of common sense and judgment, a host of contradictory decisions in daily practice, ${ }^{36}$ and the interesting but slippery problem of inferring from those decisions the corresponding philosophical commitments. Although we may conclude that differences in public health decision making can be explained as a matter of different (and sometimes non-negotiable) values, some scientific and some extrascientific, ${ }^{36}$ disclosure of philosophical commitments or "values" remains the key concern, as some philosophers who see science as social knowledge have emphasised. ${ }^{37}$

If public health professionals embrace the need to examine and proclaim their philosophical foundations, then a guide encompassing ethics, ontology, and epistemology is needed. Call it a guide to the philosophy of public health.

No such document exists. More work has been done on the ethics of public health $^{9} 111338-40$ including the ethics of screening ${ }^{41-46}$ than on ontology, a fact that may have spurred Nijhuis and Van der Maesen's appeal to that part of philosophy. ${ }^{1}$ There has, however, been a recent discussion of the role of systems theory in conceptualising the nature of epidemiological studies. ${ }^{47}$ Epistemological concerns, at least in epidemiology, have been discussed for 20 years. ${ }^{14}$

How might such a philosophy of public health arise? If efforts in the philosophy of medicine are a reasonable template, then we should expect a gradual transition through three phases. ${ }^{48}$ In the first phase, what could be called philosophy and public health, practitioners would use a philosophical idea to illuminate an issue in the practice of public health. Philosophers in turn would use a public health problem to illustrate some aspect of philos- ophy. The two disciplines would remain distinct and the analyses superficial. In the second phase, called philosophy in public health, more formal philosophical analyses would be applied to problems that comprise the "matter" of public health. This phase best represents some efforts in public health and epidemiology; the two decades long debate about the utility of Popperian philosophy comes to mind as well as the extensive efforts to examine the ethics of public health and epidemiology. In the final phase, a philosophy of public health would emerge from an examination of the discipline itself as a discipline. A philosophy of public health would consist of a general theory of public health within which the problems examined and solutions proposed in the previous phases would be incorporated and synthesised. The types of problems could be ontological, ethical, and epistemological as described in this paper. These problemsolutions in turn would provide the public health practitioner with a foundation for philosophical perspectives that presumably underlie and influence daily public health decision making.

Helpful suggestions for improving an earlier draft of this paper were made by Drs Dan Beauchamp, Mark Parascandola, and were made by
Dixie Snider.

1 Nijhuis HG, Van der Maesen LJG. The philosophical foundations of public health: an invitation to debate. 7 Epidemiol dations of public health: an invit
Community Health 1994;48:1-3.

2 Rose G. Sick individuals and sick populations. Int $\mathcal{F}$ Epidemiol 1985;14:32-8.

3 Terris M. The Society of Epidemiologic Research (SER) and the future of epidemiology. Am F Epidemiol 1992;136: 909-15.

4 Weed DL. Epidemiology, the humanities, and public health. Am f Public Health 1995;85:914-18.

5 Shy CM. The failure of academic epidemiology: witness for the prosecution. Am f Epidemiol 1997;145:479-86.

6 Rose G. Strategy of prevention: lessons from cardiovascular disease. BMF 1981;282:1849-51.

7 Marteau TM. Reducing the psychological costs. BMF 1990; 301:26-8.

8 Riis P. Mass screening procedures and programmes. In: Doxiadis S, ed. Ethical dilemmas in health promotion. New York: Wiley, 1987:171-82.

9 Beauchamp DE. Philosophy of public health. In: Reich WT, ed. Encylopedia of bioethics. New York: Simon and Schuster
ent ed. Encylopedia of bioethics.

10 O'Hagan J. The ethics of informed consent in relation to prevention screening programmes. NZ Med f 1991;104: 121-3.

11 Cole P. The moral bases for public health interventions. Epidemiology 1994;6:78-83.

2 Pellegrino ED. Autonomy and coercion in disease prevention and health promotion. Theor Med 1984;5:83-91.

13 Last JM. Ethics and public health policy. In: Last JM, Wallace RB, eds. Public health and preventive medicine. Norwalk: Appleton and Lange, 1992:1187-96.

14 Weed DL. Epistemology and ethics in epidemiology. In: Coughlin SS, Beauchamp TL, eds. Ethics and epidemiology. New York: Oxford University Press, 1996:76-94.

15 Mandelson MT, Wagenr EH, Thompson RS. PSA screening: a public health dilemma. Anпu Rev Public Health 1995;16:283-306.

16 Schroder FH. Prostate cancer: to screen or not to screen? BMF 1993;306:407-8.

17 Catalona WJ. Screening for prostate cancer: enthusiasm. Urology 1993;42:113-15.

18 Kramer BS, Gohagan JK, Prorok PC. Is screening for prostate cancer the current gold standard? - No. Eur $\mathcal{F}$ Cancer 1997;33:348-53.

19 Lange PH. Is screening for prostate cancer the current gold standard? - Yes. Eur F Cancer 1997;33:354-6.

20 Gohagan JK, Prorok PC, Kramer BS, et al. Prostate cancer screening in the prostate, lung, colorectal and ovarian cancer screening trial of the National Cancer Institute. 7 Urol 1994;152:1905-9.

21 Schroder $\mathrm{FH}$, Bangma $\mathrm{CH}$. The European randomized study of screening for prostate cancer (ERSPC). Br F Urol 1997;79 (suppl 1):68-71.

22 Wilt TJ, Brawer MK. The prostate cancer intervention versus observation trial: a randomized trial comparing radical prostatectomy versus expectant management for the treatment of clinically localized prostate cancer. F Urol 1994;152:1910-14. 
23 Voss JD. Prostate cancer: screening and prostate-specific antigen: promise or peril? f Gen Intern Med 1994;9:468-74 24 Middleton RG. Prostate cancer: are we screening and treating too much? Ann Intern Med 1997;126:465-7.

25 Vineis P. Proof in observational medicine. 7 Epidemiol Com mun Health 1997;51:9-13.

26 Mettlin C, Jones G, Averette H, et al. Defining and updating the American Cancer Society guidelines for the cancerrelated checkup: prostate and endometrial cancers. $C A$ Cancer F Clin 1993;43:42-6.

27 Chodak GW. Questioning the value of screening for prostate cancer in asymptomatic men. Urology 1993;42:116-18. 28 Woolf SH. Public health perspective: the healthy policy
implications of screening for prostate cancer. f Urol 1994;152:1685-8.

29 Woolf SH. Should we screen for prostate cancer? $B M \mathcal{F}$ 1997;314:989-90.

30 Hahn DL, Roberts RG. PSA screening for asymptomatic prostate cancer: truth in advertising. I Fam Pract 1993;37: prostate

31 Wolf AMD, Nasser JF, Wolf A, et al. The impact of informed consent on patient interest in prostate-specific antigen screening. Arch Intern Med 1996;156:1333-6.

(s) question? 7 Gen Intern Med 1995;10:295-7.

33 Pellegrino ED, Hart RJ, Henderson S, et al. Relevance and utility of courses in medical ethics: a survey of physicians perceptions. FAMA 1985;253:72-86.

34 Self DJ, Wolinsky FD, Baldwin DC. The effect of teaching medical ethics on medical students' moral reasoning. Acad Med 1989;64:755-9.
35 Schlesinger GN. Scientists and philosophy. In: Rothman KJ, ed. Causal inference. Chestnut Hill, MA: ERI, 1988:77-91. 36 Weed DL. Underdetermination and incommensurability in contemporary epidemiology. Kennedy Institute of Ethics fournal 1997;7:107-27.

37 Longino HE. Science as social knowledge. Princeton, NJ: University Press, 1990.

38 Skrabanek P. Why is preventive medicine exempted from ethical constraints? f Med Ethics 1990;16:187-90.

39 Gillon R. Ethics in health promotion and prevention of disease. F Med Ethics 1990;16:171-2.

40 Horner JS. Medical ethics and the public health. Public Health 1992;106:185-92.

41 Adami HO, Baron JA, Rothman KJ. Ethics of a prostate cancer screening trial. Lancet 1994;343:958-60.

42 Mant D, Fowler G. Mass screening: theory and ethics. BMF 1990;300:916-18.

43 Wald N, Law M. Screening, ethics, and the law. BMF 1992; 305:892.

44 Welch HG. Questions about the value of early intervention. N Engl f Med 1996;334:1472-3.

45 Edwards PJ, Hall DMB. Screening, ethics, and the law. BMF 1992;305:267-8.

46 Holland WW. Screening: reasons to be cautious. BMF 1993; 306:1222-3.

47 Weed DL. Beyond black box epidemiology. Am f Public Health 1998;88:12-14

48 Pellegrino ED. Philosophy of medicine: towards a definition. 7 Med Philos 1986;11:9-16. 